\title{
Human Relations
}

http://hum.sagepub.com/

Innovator resilience potential: A process perspective of individual resilience as influenced by innovation project termination

Gisa Moenkemeyer, Martin Hoegl and Matthias Weiss

Human Relations 2012 65: 627 originally published online 30 March 2012

DOI: $10.1177 / 0018726711431350$

The online version of this article can be found at:

http://hum.sagepub.com/content/65/5/627

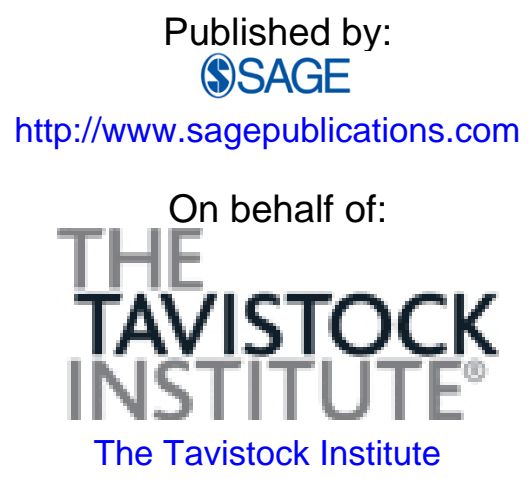

Additional services and information for Human Relations can be found at:

Email Alerts: http://hum.sagepub.com/cgi/alerts

Subscriptions: http://hum.sagepub.com/subscriptions

Reprints: http://www.sagepub.com/journalsReprints.nav

Permissions: http://www.sagepub.com/journalsPermissions.nav

>> Version of Record - May 2, 2012

OnlineFirst Version of Record - Mar 30, 2012

What is This? 


\title{
Innovator resilience potential: A process perspective of individual resilience as influenced by innovation project termination
}

\author{
Gisa Moenkemeyer \\ WHU - Otto Beisheim School of Management, Germany
}

\section{Martin Hoegl}

Ludwig-Maximilians-University Munich, Germany

\section{Matthias Weiss}

Ludwig-Maximilians-University Munich, Germany

\begin{abstract}
Innovation projects fail at an astonishing rate. Yet, the negative effects of innovation project failures on the team members of these projects have been largely neglected in research streams that deal with innovation project failures. After such setbacks, it is vital to maintain or even strengthen project members' innovative capabilities for subsequent innovation projects. For this, the concept of resilience, i.e. project members' potential to positively adjust (or even grow) after a setback such as an innovation project failure, is fundamental. We develop the second-order construct of innovator resilience potential, which consists of six components - self-efficacy, outcome expectancy, optimism, hope, self-esteem, and risk propensity - that are important for project members' potential of innovative functioning in innovation projects subsequent to a failure. We illustrate our theoretical findings by means of a qualitative study of a terminated large-scale innovation project, and derive implications for research and management.
\end{abstract}

\section{Keywords}

individual resilience, innovation failure, innovation projects, organizational behavior project termination 


\section{Introduction}

Innovation projects, i.e. projects that target the adaptation or development of new products, services, or processes (Woodman et al., 1993), are often terminated prior to completion (Shepherd and Cardon, 2009), especially when aimed at radical or discontinuous innovations (Bessant, 2008). Such project terminations are natural and often necessary as the innovation process involves high degrees of uncertainty and complexity (Clegg et al., 2002; Van de Ven and Polley, 1992). Prior research has looked at such aspects as the reasons for terminations (e.g. Balachandra and Brockhoff, 1995), success and failure factors (e.g. Shenkar and Yan, 2002), or escalating commitment to underperforming innovation projects (e.g. Sivanathan et al., 2008). These studies focus mainly on the consequences of managerial decisions regarding the immediate effects of innovation project terminations on profitability and organizational performance (Kester et al., 2009).

However, what has been largely neglected in extant literature is that innovation project terminations potentially have strong and detrimental effects on the members of terminated projects (Välikangas et al., 2009). Prior research thus seems to quietly assume that project members simply 'function' as before, with possible consequences on the people involved excluded from most research on innovation project terminations (e.g. De Reyck and Leus, 2008; Schmidt and Calantone, 1998). This is particularly noteworthy concerning future innovative activities, which must be executed by the very individuals who experienced the termination of an innovation project to which they may have dedicated much time, effort, and passion. One exception to this is Shepherd and colleagues (2009a), who look at failed entrepreneurial projects, thus shedding light on the role of negative emotions and coping self-efficacy after entrepreneurial failure, as well as on the inevitable grief process and its outcomes, which makes them pioneers in this research field. We complement their research by considering this topic from a different angle - the resilience of individuals after an innovation project termination - and thus go one step further.

The resilience of project members, i.e. the 'positive adaptation within the context of significant adversity' (Luthar et al., 2000: 543), such as an innovation project termination, is essential to prepare the ground for future innovative endeavors (Powley, 2009), as the project members, along with their motivation and capabilities, are surely among a company's most valuable resources for innovation (Verona, 1999). While resilience research largely investigated individual resilience generally, and mostly in a clinical context (Richardson, 2002), research on individual resilience in an organizational context is still at a very early stage (Avey et al., 2010b; Luthans and Youssef, 2007; Stajkovic, 2006) and has, to date, focused mainly on resilience's influence on organizational change and layoffs (Grzeda and Prince, 1997; Rush et al., 1995; Wanberg and Banas, 2000). Owing to the peculiarities inherent in innovative tasks (Drucker, 1985), we argue that, in the context of innovation, it is not possible to understand resilience by applying (existing) general resilience concepts and measures (e.g. Avey et al., 2010a; Ong et al., 2006; Wanberg and Banas, 2000). Rather, a resilience construct aligned to the unique setting of innovation, i.e. the elevated degree of unpredictability, complexity, and risk in this environment (Drucker, 1985; Van de Ven, 1986), appears necessary. It is important that such a context-specific resilience construct not only incorporates the recovery from an adverse event, but also the potential for maintaining personal innovativeness after a setback and 
the strength to cope with future setbacks, as a future project failure is likely in the innovation context.

In this study, we develop the construct of innovator resilience potential (IRP), which captures the potential for innovative functioning after a termination and for coping with future setbacks. To operationalize IRP, we identify a set of constituting components that meet three conditions: they are important for future innovative functioning (innovation), concern coping with future setbacks (consecutive resilience), and are malleable.

As a first step towards integrating the research streams on project terminations, individual resilience and innovation this article offers two main contributions. First, we contribute to the literature on innovation project termination and resilience by theoretically developing the second-order construct IRP, which is important for project members' innovative functioning in future projects after a termination. Drawing on Bandura's (1986) social cognitive theory (SCT), research on general resilience, and literature on innovation management, we theoretically identify six components that constitute IRP. By conducting a case study of a failed large-scale innovation project, we illustrate IRP's relevance as a multidimensional construct in the reality of an innovation project termination. This empirical study suggests that the IRP construct is not only theoretically coherent, but also practically relevant.

Second, we develop a process perspective of individual resilience in organizations by conceptualizing IRP also as an outcome variable that is influenced by situational and environmental factors. Much of the literature on resilience in organizations operationalizes resilience as a trait or a resource, suggesting a rather static view of individual resilience in organizations (e.g. Masten and Reed, 2002; Ong et al., 2006; Tugade and Fredrickson, 2004). We expect that not only personal resilience will influence the outcomes of a challenging situation - in our case, the termination of an innovation project - but also that the setback situation itself will influence personal resilience. This underlines the assumption that resilience should be seen as a process rather than as a stable trait (Luthar et al., 2000; Richardson, 2002; Sutcliffe and Vogus, 2003). This process perspective of IRP offers an alternative, more dynamic approach that allows for specifying antecedents of resilience (rather than its effects) in future studies, thus paving the way for the thorough investigation of the human side of innovation project terminations, and the development of actionable recommendations on how to minimize the human cost of innovation failure. Surprisingly, these aspects have been widely neglected in research on innovation project terminations to date, even though in the innovation context failure is rather the rule than an exception (Corbett et al., 2007).

This article is organized as follows. In a first step, we review existing literature and subsequently derive the IRP construct and its components theoretically. We then present our case study, setting out to illustrate IRP's components and how they are influenced by a project termination. The article closes with a discussion of this study's main theoretical and practical implications, along with limitations and an outlook.

\section{Theory}

The concept of resilience was introduced in the 1970s. After focusing on resilience in children and adolescents, it was expanded to adult research, which initially was mainly 
conducted in the field of psychiatry (Masten, 2001). Most researchers set out to explain positive adjustment in the face of traumatic experiences (Luthar et al., 2000), often measured by the absence of post traumatic stress disorder or depression (Bonanno et al., 2006). The concept of resilience has been introduced to the context of organizational research during the past decade. Since then, research on individual resilience in organizations has developed mainly into three different research streams. Representing a central construct in positive psychology (Seligman and Csikszentmihalyi, 2000; Youssef and Luthans, 2007), Luthans and colleagues embed resilience into positive psychology's application to the workplace, with resilience as one of the four parts of their positive construct, termed psychological capital (PsyCap), which they describe as 'positively oriented human resource strengths and psychological capacities that can be measured, developed, and effectively managed for performance improvement' (Luthans, 2002: 59). The second path, as taken by Wanberg and Banas (2000), examines resilience as a predictor of employee openness towards workplace changes. They measure resilience as a composite of individual-difference variables (self-esteem, perceived control, and optimism) derived from cognitive adaptation theory (Taylor, 1983), suggesting that individuals with high levels of well-being during stressful life events exhibit high levels of these variables (Wanberg and Banas, 2000). The third organizationally embedded research stream deals with the construct of career motivation of which career resilience is one component (London, 1983; Noe et al., 1990); career resilience is defined as the 'ability to bounce back after a career setback' (Grzeda and Prince, 1997: 172).

\section{Resilience as a process}

The studies in the organizational context predominantly treat resilience as a factor that influences a setback's impact on individuals (Richardson, 2002), thereby neglecting this setback's potential influence on resilience. For example, Ong et al. (2006) consider resilience as a stable trait-like construct that alters responses to daily stress. By contrast, Luthans and colleagues acknowledge resilience's malleability. Still, they mainly conceptualize it as an influencing factor on workplace outcomes (Avey et al., 2010b; Luthans et al., 2007b). However, this view of resilience as a malleable construct implies that resilience may also be conceptualized as a successful process (Luthar et al., 2000; Richardson, 2002; Sutcliffe and Vogus, 2003). In this regard, Bandura's (1986) social cognitive theory (SCT) suggests that a professional setback has the potential to influence individual resilience. According to SCT, personal factors (e.g. resilience components) may be altered by the environment (Akgün et al., 2003). In SCT, psychosocial functioning is explained in terms of triadic reciprocal causation (Bandura, 1986), meaning that 'behavior, cognitive and other personal factors, and environmental events all operate as interacting determinants that influence each other bidirectionally' (Bandura, 1988: 276). Thus, employees are both products and producers of their personality, behavior, and environment (Stajkovic and Luthans, 1998). Individual resilience may therefore be seen on the one hand as an antecedent of how a future setback affects an individual, and on the other hand as an outcome of a setback situation.

The termination of an innovation project represents such a setback, which may affect the project member's individual resilience in the innovation context. In turn, 
this resilience influences the potential of future innovative functioning and of dealing with future setbacks after having experienced an innovation project termination. This is in line with the view of resilience as a process (Richardson, 2002), which holds that, as a result of disruptions, resilience may be weakened or strengthened, thereby implying additional or decreased protection for future disruptions (Dougall et al., 2000; Moore et al., 2004). Further, we underline that 'early experience shapes later experience' (Sutcliffe and Vogus, 2003: 96), such that the development of resilience depends on an individual's history of prior experience, and that a mix of prior success and failure is required for this development. This part of the resilience process, in which resilience is influenced by an adverse event and is therefore seen as an outcome variable, has largely been disregarded in organizational research on resilience to date. This presents a stark contrast to research on resilience in clinical psychology, where the process perspective of resilience and the measurement of resilience as an outcome has found broad application (Luthar et al., 2000; Masten, 2001; Richardson, 2002). Therefore, even though stressing the process view of resilience, we focus in this study on that part of the resilience process where the setback influences IRP as illustrated in Figure 1. This will also form the conceptual domain of our case study. The gray shaded area indicates the ongoing process, the setback situation influences IRP, which, in turn, influences the potential of future innovative functioning and future coping.

In one of the rare empirical studies to examine resilience as an outcome variable in the workplace, Harland et al. (2005) used a student sample of part-time MBAs to examine which aspects are perceived as helpful in dealing with difficult or challenging past work experiences. They found that leader behavior may strengthen individual resilience when dealing with stressful events. Another example of empirical research on resilience as influenced by stressful events is provided by Moore et al. (2004), who examine the influence of layoff contact on employee reactions to subsequent layoffs. They found that people who had experienced contact with layoffs in the past (either by being laid off

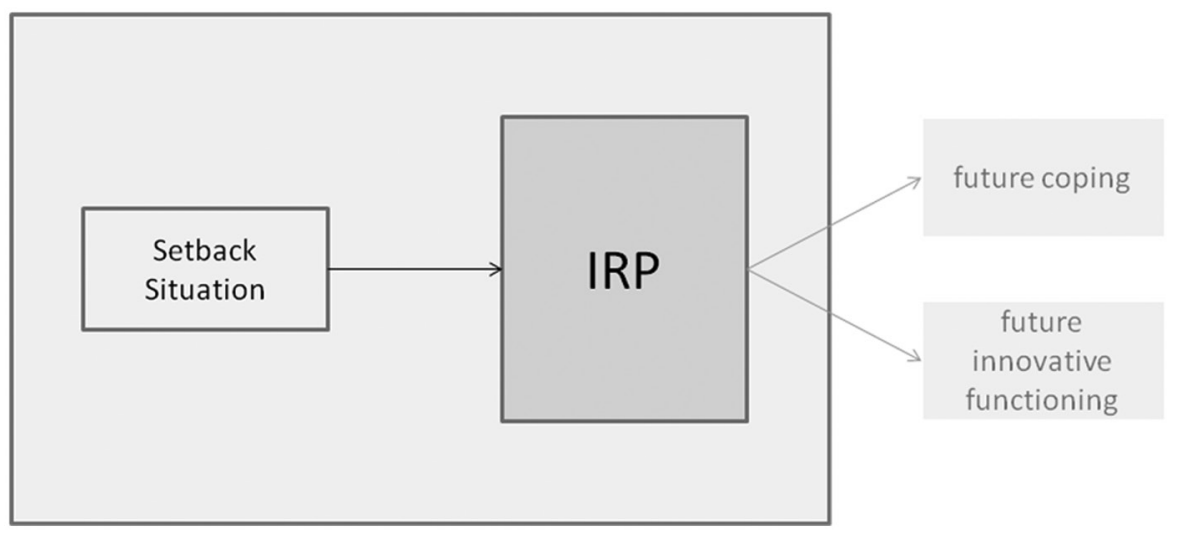

Figure I The resilience process. 
themselves or by seeing colleagues being laid off) reported lower job security and higher levels of role ambiguity, intent to quit, depression, and health problems after a subsequent layoff situation, thereby suggesting a reduced level of resilience after the setbacks had occurred. An opposing view, which nonetheless also supports the process perspective of resilience, derives from the literature on post-traumatic growth or thriving. This literature describes situations in which an individual's level of functioning after an adverse event exceeds the individual's level of functioning before the adverse event (Carver, 1998), suggesting that people may learn from setbacks how to deal effectively with such situations (Corbett et al., 2007), thereby developing a higher degree of resilience (Dougall et al., 2000).

\section{Innovator resilience potential (IRP)}

Throughout this article we define our focal construct IRP by adapting the definition of resilience by Sutcliffe and Vogus (2003) to the innovation context: IRP is the potential for future innovative functioning and coping with future setbacks after having experienced a professional setback. In the innovation context, such a setback commonly refers to an innovation project failure, i.e. the deliberate decision to terminate or substantially change an innovation project prior to its completion (Kumar et al., 1996). In this context, we define an innovator as a person who, in a professional capacity, works on or incites innovative tasks.

As resilience has not yet been considered in the context of innovation, it was necessary to develop a definition and an operationalization specific to this setting. Luthar et al. (2000) recommend that 'the term 'resilience' should always be used when referring to the process or phenomenon of competence despite adversity' (p. 554). Yet, for each context, it is necessary to define what competence means in the specific research setting. We will do this by identifying six components that operationalize (the contextspecific concept of) IRP. These six components indicate the degree to which an individual has the potential to perform again in future innovative tasks (i.e. future innovative functioning) and to cope with future setbacks (i.e. future coping). It is important to note that we see IRP as a necessary but not sufficient condition for future innovative functioning and future coping. Situational aspects of such a future setback, such as leader support during a setback episode, are also likely to affect the degree of actual future innovative functioning and future coping after such a future setback. Therefore, we assume that IRP is a prerequisite for future innovative functioning and coping with future setbacks, but does not equal it.

As a latent second-order construct, IRP comprises six first-order components. The premise for identifying the constituting components has been that they relate to resilience (better coping with future setbacks) as well as to innovation (future innovative functioning) and that they are malleable in nature (being possibly influenced by the setback), which corresponds to our process conceptualization of resilience as explained above. As such, IRP incorporates state-like qualities that are essential prerequisites for innovative functioning after professional setbacks such as innovation project terminations, thus representing fundamental prerequisites for accomplishing subsequent innovative tasks (Amabile, 1988). 
Resilience research at the organizational level already acknowledges the close connection of resilience and innovation, in contrast with research at the individual level. Diamond (1996: 221), for example, sees organizational resilience as 'the ideal context for innovation.' Hamel and Välikangas (2003: 55) even consider resilience as one of three essential forms of innovation: 'Resilience refers to a capacity for continuous reconstruction.' They emphasize that success usually doesn't breed success, but rather follows failure in the innovation process (Hamel and Välikangas, 2003). This underlines how closely interlinked the two concepts are. In addition to this, for each component of IRP there are research findings reported in the literature providing evidence for facilitating positive adaptation. Specifically, each component of IRP must enable future innovative functioning as well as the ability to deal with future setbacks. Hence, qualities to be included in IRP must be part of the interface of malleable innovation and resilience qualities, as depicted in Figure 2.

Figure 2 depicts 'resilience qualities' as well as 'innovation qualities' which, taken together, represent the personal qualities necessary for resilience and innovation. Regarding the identification of personal qualities supportive of innovation, which are depicted by the left circle in Figure 2, there exists a vast body of research that broadly distinguishes two categories of qualities (Miron et al., 2004). One category contains creativity and other qualities that are assumed to facilitate creative thinking and thus idea genereation, such as expertise (Amabile, 1988) and cognitive style (Witkin and Goodenough, 1981). The second category includes qualities that are assumed to foster the implementation of novel ideas, such as self-confidence (Mumford and Gustafson, 1988) and the ability to promote innovations (Hauschildt and Kirchmann, 2001). Resilience qualities refer to a person's 'selective strengths or assets to help them survive adversity' (Richardson, 2002: 309). They are represented by the circle on the right hand side of Figure 2. In this context, a large list of qualities supposed to help individuals recover from adverse events like, for example, self-control (Baumeister and Exline, 2000) and happiness (Buss, 2000) can be found in the literature.

There are many overlapping qualities, represented by the intersection of the two circles in Figure 2, as innovation is highly related to setbacks and resilience. Some of these qualities situated at the intersection of resilience and innovation qualities, and thus

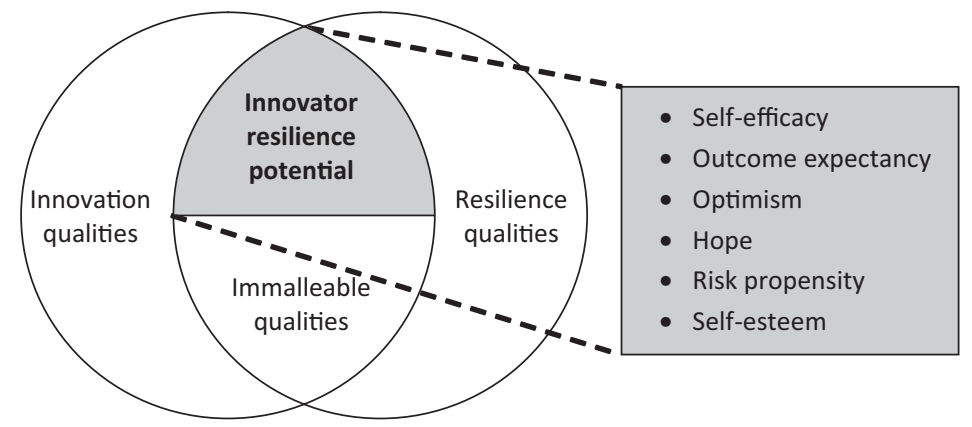

Figure 2 Innovator resilience potential. 
fulfilling this necessary condition to constitute IRP, however, are relatively stable over time and thus not malleable as required, such as employees' need for achievement (Phillips and Gully, 1997), or personality (McCrae and John, 1992). These make up the lower half of the circles' intersection in Figure 2. For example, in the literature, the need for achievement strength is generally seen as a stable attitudinal variable of individuals unlikely to be affected by situational aspects (Begley and Boyd, 1987; Mannheim et al., 1997), and personality has repeatedly been shown to be fairly stable in adult individuals (Hampson and Goldberg, 2006; McCrae and Costa, 1982). Hence, constructs that are suggested in the literature on individual resilience and innovation to represent a trait (rather than being state-like) are not included in IRP, as they are assumed to be unaffected by a setback such as an innovation project termination and would therefore not fit the process view of resilience. Applying these premises, we identified six components that represent both innovation and resilience state-like qualities, thus positively affecting innovative functioning in future innovative endeavors after professional setbacks (which, in turn, are likely to be affected by such setbacks): outcome expectancy, self-efficacy, optimism, hope, self-esteem, and risk propensity. They are represented by the upper half of the circles' intersection in Figure 2, which is shaded grey. Together, these components constitute IRP and thus build the potential for future innovative functioning and coping; in the following section we will present these components in detail. Importantly, while IRP is assumed to facilitate innovative functioning and coping with future setbacks in subsequent innovation projects, it is not considered equal to them. In innovation projects, there are many environmental factors that might exert considerable influence on an individual's innovative functioning and coping with setbacks in the future, such as team processes (Hoegl and Gemuenden, 2001) or leadership aspects (Hung, 2004).

Outcome expectancy and self-efficacy. Self-efficacy and the related construct of outcome expectancy can be ascribed to Bandura's work, the underlying social learning theory (Bandura, 1982) and SCT (Bandura, 1986). Self-efficacy is concerned with self-judgments of how successfully one can perform one's job (Riggs and Knight, 1994). Efficacy expectations determine how much task-related effort will be expended and how long that effort will be sustained despite disconfirming evidence (Bandura, 1977). Outcome expectancy refers to 'a judgment of the likely consequence such performances will produce' (Bandura, 1977: 211). In the present context, self-efficacy represents an individual's belief that he or she has the capabilities to fulfill the assigned tasks in an innovation project; outcome expectancy represents the belief that the fulfillment of one's assignments produces the desired outcomes, such as recognition and project completion. The malleability of these constructs was shown, e.g. by Riggs and Knight (1994), who found that failure affects the levels of individual efficacy beliefs as well as outcome expectancy.

Both self-efficacy and outcome expectancy relate to the control a person experiences in a given context (Bandura, 1977). They are necessary for considering a situation as changeable. In turn, this is particularly important in the present context, as innovation is often driven by the desire to achieve something that might 'change the game' (O'Connor and McDermott, 2004: 16). In addition, high self-efficacy is widely acknowledged as a facilitator of individual creative action (Bandura, 1997; Tierney and Farmer, 2002), which is a necessary prerequisite of innovation (Amabile, 1988). Hence, high 
outcome expectancy and self-efficacy are very likely to facilitate a project member's ability to innovate. Concerning resilience's link to high outcome expectancy and selfefficacy, self-efficacy is used as a component of career resilience in Grzeda and Prince's (Grzeda and Prince, 1997) validation of their career motivation measure. Furthermore, Luthans and colleagues (Luthans et al., 2007a) consider self-efficacy as a component of PsyCap. Outcome expectancies associated with different behavior types are likely to affect which behaviors individuals will utilize and thus the way in which they choose to apply their cognitive competencies (Freitas and Downey, 1998). This enables individuals to score high on outcome expectancy, applying their cognitive competencies more effectively (Freitas and Downey, 1998), which is likely to make them more resilient in future adverse situations.

Optimism. The construct of optimism was introduced by the anthropologist Lionel Tiger as 'a mood or attitude associated with an expectation about the social or material future - one which the evaluator regards as socially desirable, to his advantage, or his pleasure' (Tiger, 1979: 18). It is related to cognitive processes as well as to emotions (Stajkovic, 2006). In this research, we refer to the explanatory style of Seligman, Peterson, and colleagues (Seligman, 1998). This more state-like approach to optimism depends on the attributes an individual uses 'to explain why certain events occur . . past, present or future' (Luthans et al., 2007b: 87). According to Seligman (1998), an optimist attributes positive events to personal, permanent, and pervasive causes and negative events to external, temporary, and situation-specific factors. For pessimists, the attribution is the opposite. These attributional styles are malleable individual characteristics that may be influenced, for example, by stress and trauma (Peterson, 2000) or therapeutic interventions (Seligman et al., 1988).

Optimism was shown to mediate the relationship between supportive climate and performance, and innovation outcomes (Luthans et al., 2008). Furthermore, prior work suggests positive relationships among optimism, goal engagement, and attainment of high-priority goals (Geers et al., 2009). All these aspects are essential for developing successful innovations. Concerning the context of resilience, Wanberg and Banas (2000) used optimism to define and measure resilient individuals, while Luthans et al. (Luthans et al., 2007a) see it as a component of PsyCap. Furthermore, strong optimism is assumed to generate a state of vigor and resilience (Peterson, 2000).

Hope. Being closely related to goal-setting theory (Snyder et al., 1991; Stajkovic, 2006), hope is defined as a 'cognitive set that is based on a reciprocally derived sense of successful (a) agency (goal-directed determination) and (b) pathways (planning to meet goals)' (Snyder et al., 1991: 570). While the agency aspect closely relates to self-efficacy and optimism (Peterson, 2000; Stajkovic, 2006), the pathway aspect is particularly distinct. Hopeful individuals find out 'what is to be done and how to do it' (Stajkovic, 2006: 1209). They therefore set goals and identify ways to achieve these goals. Several scholars argue that hope is malleable, following Snyder's state concept of hope (Snyder et al., 1996), which has been demonstrated, for example, by Luthans et al. (2006).

Hope was shown to positively influence survival beliefs (Range and Penton, 1994). Even though the innovation process does not threaten the lives of those involved, it 
involves many obstacles and ill-defined problems, which make a kind of survival belief indispensable in order to persist in the face of adversity. Especially the pathway component 'allows for rekindling of determination and willpower even when faced with blockages, as additional alternative pathways have been proactively determined' (Youssef and Luthans, 2007: 793). Hope also allows one to turn obstacles into challenges and learning opportunities (Luthans et al., 2007a), which is essential in innovation (Amabile et al., 2002). Stajkovic (2006) includes hope in his higher-order core confidence construct, suggesting that hope shares a common confidence core with resilience. Furthermore, hope also represents a component of PsyCap (Luthans et al., 2007b).

Self-esteem. Self-esteem, which is defined as a person's perception of his or her self-worth (Stajkovic, 2006), may be distinguished from self-efficacy, which refers to confidence in one's abilities. Self-esteem relates to judgments of self-worth - liking or disliking oneself (Bandura, 1997; Braden, 1998). According to Heatherton and Polivy (1991), self-esteem may be subject to temporary changes, thus representing a malleable construct.

Self-esteem has been shown to relate positively to motivation and creativity (Braden, 1998; Erez and Judge, 2001), which are key determinants of innovative functioning. Hence, self-esteem appears to be a crucial prerequisite for successful engagement in innovation projects. Furthermore, self-esteem was used by Wanberg and Banas (2000) to define and measure high individual resilience, with a higher level of self-esteem corresponding to higher resilience levels.

Risk propensity. The propensity to take risks 'involves calculated actions to make effective decisions that promote goal attainment with the clear recognition of the potential of damage, setbacks, and other losses' (Tjosvold and Ziyou, 2007: 655). The extent of an individual's risk propensity depends on contextual factors such as the organizational environment, for example, psychological safety in a work group (Edmondson, 1999), thereby pointing to this construct's malleability. Further, negative emotions were found to influence risk adversity (Lerner and Keltner, 2001).

The propensity to take risks strongly correlates with general flexibility (Rybowiak et al., 1999) and promotes innovation as well as recovery from mistakes (Tjosvold and Ziyou, 2007). This is further underlined by risk propensity representing a component of London's (1983) career resilience construct, which refers to an individual's resistance to career setbacks. Consequently, several empirical studies demonstrate that risk propensity strongly relates to new product innovativeness and seems to be a key factor for successfully developing novel products and solutions (e.g. Sethi and Sethi, 2009). This connection has been established particularly in the literature on entrepreneurial innovation (Hung, 2004) and entrepreneurs' responses to failure (Corbett et al., 2007; Shepherd et al., 2009a). For example, Simon et al. (2000) emphasize the positive effect of experiencing failure for future entrepreneurial activities. Furthermore, the importance of resilience for entrepreneurs to start subsequent ventures after business failure is an important approach to explain why many entrepreneurs do not lose their overconfidence when trading-off risks and opportunities when founding new ventures (Hayward et al., 2010).

Despite similarities and some overlap between the six IRP components, we consider them as distinct aspects of IRP. This is similar to Luthans and colleagues' conceptualization 
of PsyCap as a multidimensional construct comprising four components considered positive psychological resources (Avey et al., 2010b). We will now embed the theoretically derived concept of IRP by presenting the case example of the termination of a large-scale innovation project in an internationally leading hospitality company.

\section{Methods}

We conducted an in-depth case study to illustrate how the six components of IRP are affected by a termination. Interviews were conducted after the termination of a largescale real-life innovation project. This method was chosen primarily for two reasons. First, the research question has not been addressed in previous studies, which calls for a qualitative approach to extend and elaborate existing theory (Eisenhardt and Graebner, 2007; Glaser and Strauss, 1967; Silverman, 2000). As such, our objective in this case study research was to supplement our theory development. Second, an inductive case study is suitable for the investigation and identification of the complex social processes involved in the organizational context surrounding these processes (Eisenhardt and Graebner, 2007) as most research questions deal with reciprocal interactions between the organizational context and individual behavior (Schneider, 1983).

\section{Case setting}

The unit of analysis was a terminated innovation project with several subprojects in a global hospitality company. We chose a single case design to capture the circumstances and conditions of an innovation project termination that seem typical for such occurrences in order to illustrate the IRP concept's practical relevance (Yin, 2003). Further, by studying a project termination in a single company, the structural company and industry characteristics can be held constant, thus increasing internal validity of the findings compared with analyzing projects from different companies or industries (Yin, 2003). Internal validity is further strengthened by the theoretically derived research framework and questions, for which the specific circumstances of this termination provide an excellent case to examine (Gibbert et al., 2008; Yin, 2003). As different subprojects existed, which were in different stages of progress when the termination occurred, a variety of insights, opinions, and feelings could be found and analyzed in this case study. Although there is always a trade-off between internal and external validity, incorporating these different subprojects in the analysis and thus pursuing a 'nested' approach enabled us to extend generalizability of findings to other contexts (Yin, 2003) while at the same time holding constant company and industry influences. The provision of a detailed case description also supports external validity (Cook and Campbell, 1979).

As resilience needs to be investigated after the trigger event has occurred in order to examine resilience as an outcome variable, the participants were interviewed after the project's termination. Interviews were conducted with seven key people in the innovation project in the focal European country. On the company side, our research was supported by the head of human resource development and the top management, which allowed us to have interviewees from all hierarchical levels - including the lowest, i.e. a team/staff member, and highest, i.e. the director (CEO) - of the focal country. Table 1 
shows the different positions the interviewees held in the company and their function during the project. The three branch directors represent classical middle management positions in the company. The branches were of different sizes and belonged to different brands, thus the hierarchy of these three positions within middle management also varied. This cross-section of functions and positions in the innovation project enabled us to gather data from a multitude of perspectives on the innovation project termination. Interviewees were selected in cooperation with the head of human resources development, who was involved in the innovation project from the outset.

\section{Data collection}

In order to maximize reliability of results, multiple sources of evidence were used and a case study database was created (Gibbert et al., 2008; Yin, 2003). Open-ended interviews, site visits, site observations, documents, and rich archival records were the sources available for the investigation of this in-depth case study. Documents were provided by interviewees and derived from the company's intranet and the media. In total, more than 1000 pages of documentation were reviewed. All interviews were semistructured (Wengraf, 2001) and the questions were adjusted to interviewee role. We developed the interview guideline questions by means of a critical incident approach (Flanagan, 1954), asking interviewees for aspects that influenced the IRP components after the termination and its future impact. Sample questions included: 'Do you have the feeling that you can influence outcomes in the company?'; and 'Do you currently have work goals? What are they?' To maximize the insights gained from every interview, the interview guideline was adjusted as the research progressed. Interviews were taperecorded and transcribed. During the interviews, the interviewer took notes to complement the records.

The total length of the recorded interviews was 573 minutes, and the transcripts yielded 273 pages of text. All interviews were conducted by the same interviewer at the interviewees' workplace and took place one year after the innovation project's termination. The interviews were accompanied by on-site observations that helped us interpret and understand the case context. Two interviews were conducted in the focal country's headquarters and the other five interviews at local sites in major European cities. Furthermore, six additional on-site visits (between one and three hours in duration) at the

Table I Interviewees functions during the project and positions

\begin{tabular}{llll}
\hline & Gender & Position & Function during the project \\
\hline I & Male & Director (CEO) & Initiator of the project FI \\
2 & Male & VP HR & Head of an unsuccessful subproject \\
3 & Male & Local branch director & Overall project leader \\
4 & Male & Local branch director & Head of an unsuccessful subproject \\
5 & Male & Local branch director & Head of a successful subproject \\
6 & Male & HR Development manager & Coach of the project \\
7 & Female & HR Manager & Member of an unsuccessful subproject \\
\hline
\end{tabular}


company's headquarters helped us gain a deeper impression of the company's culture, as well as a picture of the changes that recently occurred in the company, and enabled us talking to some employees who were not involved in the terminated project. These discussions were informal and facilitated our understanding of the surroundings of the innovation project and the company's current situation.

\section{Data analysis}

Interviews were fully transcribed and analyzed. The data analysis started with a review of the interview transcripts. The collected responses were then content analyzed (Neundorf, 2002) by identifying key words and phrases in each response related to the IRP components, and a 'miscellaneous' category for phrases not matching any of the six IRP components. Interview data were categorized using the qualitative research software NVision. Data were double-coded by two PhD students who were blind to the study's purpose. Cohen's kappa for interrater reliability was calculated. An acceptable value of $\kappa=.83$ was found (Lombard et al., 2002). Passages coded differently by the two coders were discussed among the coders and the researchers to obtain a consensus. After coding, the most representative and illustrative quotes were selected. In this process, no further category emerged from an analysis of the 'miscellaneous' category for incorporation into the IRP construct. In general, we found that the interviewees provided themes that followed a common thread. This demonstrated that there was substantial agreement and convergent statements among interviewees concerning the topic despite the different positions and perspectives they had in the innovation project, which further reflects validity of the collected data (Gibbert and Ruigrok, 2010; Yin, 2003). Documents, including organizational charts, official letters, reports, and project booklets were used to cross-check, verify, and complement the information retrieved in the interviews.

\section{Case description: The rise and fall of 'Foster Innovation'}

\section{Project idea and goals}

In 2005, the company CEO initiated a companywide project with the purpose of fostering innovation and maintaining the company's (leading) market position. Each country was free to conceive and implement its individual innovation initiatives. The director of our focal country initiated a nationwide innovation project 'Foster Innovation' (FI) (name changed), which sought to get every employee to submit ideas. The entire project was strictly voluntary - everyone was free to choose his or her degree of participation. The innovation project pursued two main goals in the focal country: The first goal was 'to set new standards as the market leader and to be one step ahead of our competitors' (project booklet). The generation and implementation of product ideas and organizational innovations were the means to achieve this objective. The second goal was to readjust the company culture and to stimulate deep motivation throughout the entire workforce by involving all interested employees, regardless of their function and their hierarchical position in the company. Table 2 provides a timeline of key events during the innovation project's progress. 
Table 2 Timeline of key events during the project

\begin{tabular}{|c|c|}
\hline Month & Event \\
\hline 0 & Initiation of the project 'Foster Innovation' in the worldwide headquarters country. \\
\hline 2 & $\begin{array}{l}\text { Planning of the project 'Foster Innovation' in the focal country (country director, head } \\
\text { of HR development, and publicists). }\end{array}$ \\
\hline 4 & Kick-off Convention, 400 branch directors and managers set up a steering committee. \\
\hline 7 & $\begin{array}{l}\text { Appointing a project leader (branch director); } \\
\text { sending out the request for the election of an ambassador from every branch. }\end{array}$ \\
\hline 8 & $\begin{array}{l}\text { Project leader begins to work on the project full time; } \\
\text { workshops with the ambassadors. }\end{array}$ \\
\hline 9 & $\begin{array}{l}\text { Brainstorming workshops in the branches by ambassadors; } \\
\text { consolidation of ideas within regions and with steering committee. }\end{array}$ \\
\hline 9 & $\begin{array}{l}\text { Presentation of } 43 \text { ideas to the board; board decides on six core topics to work on in } \\
\text { subprojects (including the three topics mentioned most frequently by employees). }\end{array}$ \\
\hline 10 & Subprojects begin work. \\
\hline 10 & $\begin{array}{l}\text { Meeting in the worldwide headquarters country where all country subsidiaries } \\
\text { presented their initiatives. }\end{array}$ \\
\hline 12 & $\begin{array}{l}\text { Publishing of the project booklet, with information about the project, the subprojects, } \\
\text { its goals, and progress. }\end{array}$ \\
\hline 13 & $\begin{array}{l}\text { The two project initiators at worldwide headquarters leave the company; } \\
\text { budgetary negotiations due to financial problems in the focal country, which lead to } \\
\text { the cancellation of budget for the project. }\end{array}$ \\
\hline $14 / 15$ & $\begin{array}{l}\text { Apprehension about termination of the project; } \\
\text { discussions within some project groups about termination. }\end{array}$ \\
\hline 15 & Debriefings with project members in some subprojects. \\
\hline 16 & Official letter from the country director about setting the project on hold. \\
\hline
\end{tabular}

\section{Start and kick-off in the focal country}

First, a manager from the focal country was appointed project leader. He was taken out of his regular position to assume the role of the project leader and reported directly to the board member responsible for the project. Eventually, in every branch office in the focal country voluntary workshops (in their locations and departments) were organized to which every employee - from apprentice to director - was invited, to take part in and generate innovative ideas. The branch office workshops were generally characterized by high participation, documenting a general belief in management's commitment to this innovation project and its importance. Thereafter, the ideas were consolidated, first within each region and then countrywide, to generate a list of ideas that could be presented to the board. This finally led to presenting as many as 43 ideas to the board, to show the respect for employees' dedication and ideas. In a workshop characterized by passion, three regional representatives, the members of the steering committee, the project leader, and the board members discussed the ideas. Finally, the board members decided on six core topics. Two examples for subprojects are: 'Modern models of working hours and child care' with the goal of enhancing work-life balance and easing the re-entry of mothers returning from maternity leave (not successfully completed), and 'Initiation of a trend scout division' with the aim to establish a new division that searches for innovations in the hospitality sector. This latter subproject was the only successfully 
completed one. Its project team even won a national prize with its innovative ideas, which were generated in cooperation with high school pupils. For each of the six core topics, a management board member was appointed as a so-called godfather, to provide oversight and support. All employees were invited to apply for the team of one subproject. Five months after the outset, a project booklet containing information about the innovation project was published. Thus, at that moment, all employees were well informed about FI's progress, initial results, and the future.

\section{Problems and termination}

Shortly after the release of the booklet, the first problems occurred. At the world-wide headquarters, the company CEO and the VP Europe left the company. Rumors about FI's future began to spread in the focal country, because the global innovation project had been initiated by the departing company CEO. Headquarters allocated no further budget to FI in the focal country. At almost the same time, during budgetary negotiations in the focal country, it became clear that the business results (revenue and profit) were below expectations. The board and the country director felt they had no alternative but to cut expenses and to cancel the following year's FI budget. However, up to this point, no board member considered terminating FI, and the project work continued. As the situation could not be rectified swiftly, a reorganization of the branch was initiated and several employees had to leave the company. As it was hard to find reasons to justify expenses on an innovation initiative such as FI when employees were laid off, the country director wrote an official letter to all employees, which said that owing to the difficult situation FI was put on hold. However, even though the company bounced back during the same year with the highest revenue ever, the country director left the company in the middle of the following year, owing to disagreements with the worldwide headquarters. He was therefore unable to relaunch the FI project. In the end, only one subproject was successfully completed, as it was near completion when the decision to stall the overall project was taken. The only communication of the termination was the country director's letter and a final meeting by the project leader with regional representatives. In some subprojects, a debriefing took place, while in others responsible managers spoke to some team members. In other subprojects, however, the communication was merely informal, and most project work phased out prior to official termination.

\section{The innovation project termination and innovator resilience potential}

The findings of our case study support the conceptual arguments from the literature that led us to specify the components of the IRP construct, by showing how the termination of an innovation project affected the six components of IRP. This supports our theoretical construct illustrated in Figure 2, where IRP is represented by the malleable part of the intersection of the two circles of innovation and resilience qualities (grey shaded area). To illustrate our findings we embedded the most informative quotes from the interviewees into a matrix in Table 3. Each row represents one of the six IRP components. The first 


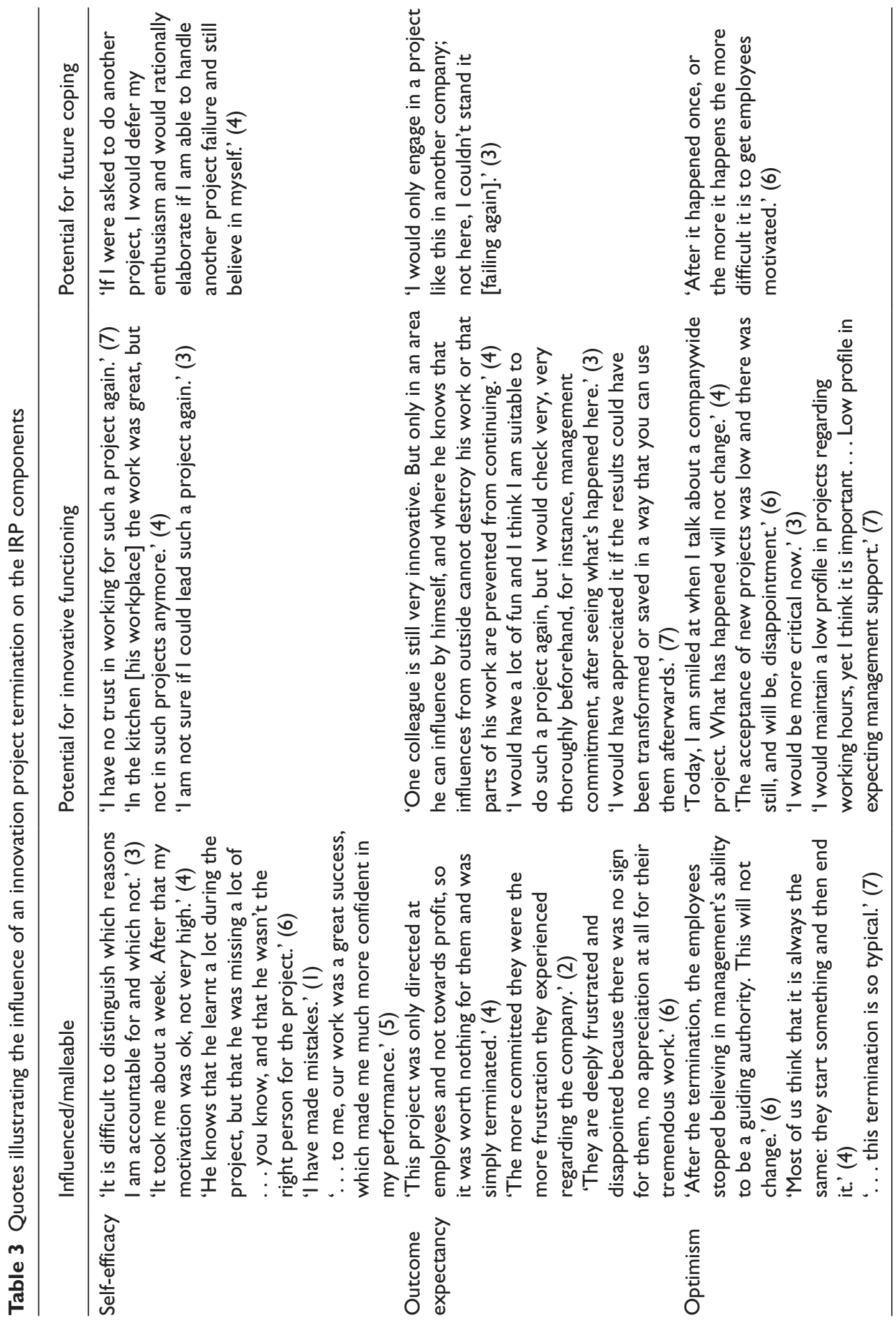




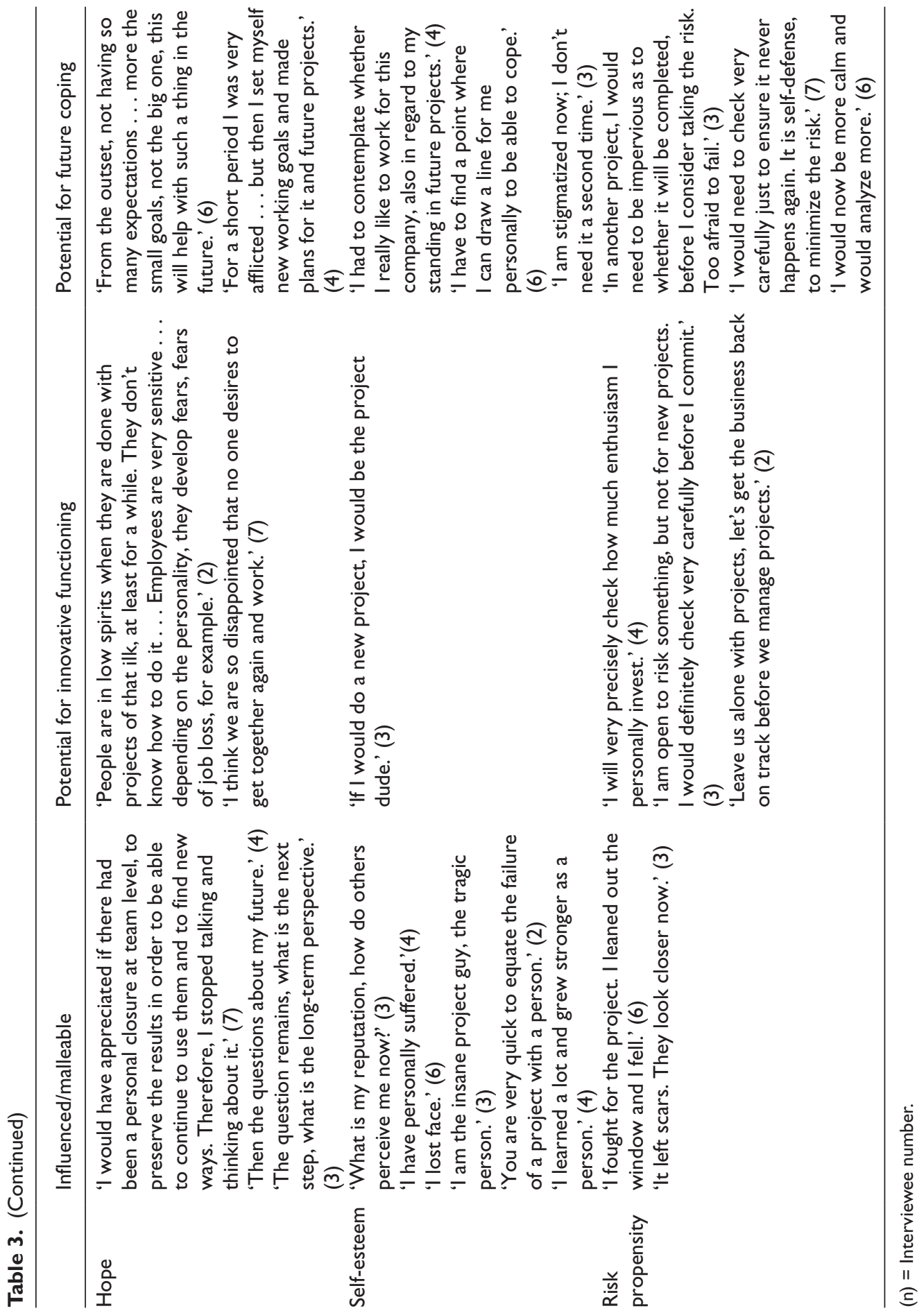


column shows how the factors were affected by the termination. Columns two and three indicate how the negatively affected IRP components influenced the individuals' potential for future innovative functioning and future coping.

Thus, as illustrated by the interview quotes in Table 3, all six IRP components were affected by the innovation project's termination (column 1), and this impact left its mark on individuals' potential for future innovative behavior, and future coping (columns 2 and 3). Specifically, the quotes reflect various influences of the innovation project termination on the involved actors. In this case, for example, the team members' self-efficacy was challenged in two ways - their own experience of failure: 'I have made mistakes'; and seeing others fail: 'He knows that he learnt a lot during the project, but that he was missing a lot of . . . you know, and that he wasn't the right person for the project.' Both experiences are likely to lessen the expectation to successfully accomplish a future task (Bandura, 1977). In this case, self-efficacy and outcome expectancy depended largely on the extent of individual control over the course of the project. Furthermore, not knowing to what extent one's own performance (negatively) affected the innovation project's termination (and thus may have led to the innovation project's termination) jeopardized individual self-efficacy and outcome expectancy: 'It is difficult to distinguish which reasons I am accountable for and which not.'

Furthermore, the interview quotes suggest that an optimistic view is important for full engagement in future innovative endeavors, to fight for new projects and, particularly, how such optimism may be compromised by a termination: 'Most of us think that it is always the same: they start something and then end it.' Without the belief that good things will result, engagement tends to be reduced. A realistic assessment of the situation is generally needed in order to develop or maintain realistic optimism after a setback.

Similarly, the interviews demonstrate how important hope is for engaging in new innovation projects, which are essential for company advancement. This makes the impact of a termination on this IRP component even more problematic: 'The question remains: what is the next step, what is the long-term perspective.' Clearly, the self-esteem of those involved mostly suffered severely, owing to the innovation project's termination. Finding words for what they experienced during and after termination, e.g. 'I lost face' or 'I have personally suffered', these people demonstrate a sharp decline in how they see and value themselves or perceive how they are seen by others in the organization. The quotes also point to a more cautious posture adopted after the termination, with apparently impeding consequences regarding their potential for future innovative functioning: 'I am open to risk something, but not for new projects.'

What also becomes evident from interviewee quotes is that there is some overlap between the components, as explained in the sections above (e.g. hope, self-efficacy, and optimism). While each component addresses a unique aspect of IRP, the components are also conceptually related to one another, thereby integrating to the overall IRP construct. This is similar to Luthans and colleagues' conceptualization of PsyCap as a multidimensional construct (Avey et al., 2010b).

A further finding of our case is that the project termination mainly influenced project members' IRP negatively. One exception is the interviewee of the successfully finished subproject. Besides showing the general malleability of the IRP components, this supports our assumption that project terminations have the potential to influence 
project members' IRP. In this vein, whether the interviewees were involved in a successful subproject or in a terminated subproject made a considerable difference on how the IRP components have been influenced. Being a member of a (un)successful subproject can even lead to opposing experiences and changes in IRP. The positively framed quote in Table 3 can be allocated to the member of the successful subproject. He states, regarding self-efficacy: 'To me, our work was a great success, which made me much more confident in my performance.' In contrast, an interviewee who experienced the termination as a failure recalls: 'I have made mistakes.' These two quotes show that these people's self-efficacy has been influenced quite differently. The way in which these interviewees experienced the overall termination of the innovation project therefore influenced them and their IRP components. Another example of how the termination was experienced differently, this time regarding self-esteem, is the following: 'I learned a lot and grew stronger as a person' versus 'I have suffered personally'. These two individuals represent two very different ways in which self-esteem can be influenced by a termination, even though they were both members from terminated subprojects.

\section{Discussion}

\section{Theoretical implications}

By specifying the IRP construct, this article contributes to the literature on project terminations and innovation management and provides an important advancement in this line of research. As innovations are essential for most companies (Eisenhardt and Tabrizi, 1995) and employees are one of the most important resources for innovation (Verona, 1999), it is important to maintain or strengthen IRP after the likely occurrence of an innovation project termination. Further, IRP is not only important concerning the potential for future innovative functioning and future coping, as argued in this article and illustrated in the case study. The six IRP components (self-efficacy, outcome expectancy, optimism, self-esteem, hope, and risk propensity) may, in turn, well be affected themselves by a termination. This addresses the identified research gap, i.e. what consequences an innovation project termination has for the project members and their subsequent innovative work. This view is in line with SCT, as it shows the reciprocity of the situation, personal factors, and behavior (Bandura, 1988).

In contrast to a major part of literature on resilience in organizations, that ranks resilience among traits, capabilities, attitudes, or resources that influence how individuals react to a setback (e.g. Avey et al., 2009; Coutu, 2002; London, 1983; Noe et al., 1990; Ollier-Malaterre, 2010; Ong et al., 2006; Stajkovic, 2006; Weick, 1993; Youssef and Luthans, 2007), we explicitly build on a process perspective of individual resilience that enables conceptualizing IRP as an outcome variable that is influenced by situational and environmental factors. This first part of the resilience process, in which resilience is influenced by an adverse event, has been largely disregarded in organizational research. This is in stark contrast to research on general depression, where the measurement of resilience (e.g. by the absence of depression) after a setback is fairly established in the literature (Masten, 2001; Richardson, 2002). We therefore contribute to the literature on 
resilience in organizations by introducing a process perspective of individual resilience into this research field. In the given context, it is reasonable to expect that the IRP construct is affected by an adverse event, as all its components are malleable. This assumption is illustrated by the study results, which show that interviewees consider the constructs that constitute IRP being affected by the termination. Finally, to our best knowledge, this is the first study to examine the resilience construct in an innovation setting, which allowed the identification of aspects of resilience specific to this setting, such as the importance of risk propensity.

This approach also allows for studying innovation project terminations' influence on individual project members. This aspect has been largely neglected in the literature on innovation project termination to date (Green et al., 2003), with the exceptions of recent studies by Shepherd and colleagues (Shepherd, 2009; Shepherd and Cardon, 2009; Shepherd and Kuratko, 2009; Shepherd et al., 2009a, 2009b), who chose a different approach to address this problem. Our study focus complements their research, which focuses on the grief process and individual learning. Both approaches appear worthwhile to shed light on future innovative functioning and the commitment to future innovation projects after termination (Shepherd and Kuratko, 2009; Shepherd et al., 2009a). We also expand Shepherd and colleagues' focus on failed entrepreneurial projects by considering innovation project terminations in mature companies.

In this regard, we believe that the reason for the termination is likely to result in notable differences in an innovation project termination's impact on project team members. Most importantly, whether such team members mention project-endogenous causes (e.g. poor performance of team members) or project-exogenous reasons (e.g. changes in top management, such as in the present case example) entail highly different consequences. Attribution theory (Rotter, 1966; Weiner, 1985) suggests that attributing external causes for termination (i.e. beyond the control of innovation project team members) has less negative impact on variables connected with individuals' beliefs about their capabilities, or with their perception of self-worth, such as self-efficacy or self-esteem (McFarland and Ross, 1982). In contrast, external failure attribution is very likely to have stronger detrimental effects on innovation project team members' outcome expectations, inducing a feeling of hopelessness and resignation when experiencing that the perception of performing well does not lead to goal achievement (Maddux et al., 1986; Weiner, 1985). Regarding the internal attribution of reasons for innovation project termination, the reverse should be the case. While both attributions are likely to affect IRP, they nonetheless are expected to do so in different ways, thereby pointing to distinctive countermeasures to protect and restore IRP in the context of an innovation project termination, depending on the reasons underlying such a termination.

One contribution of this study relates to the individual research streams, i.e. resilience in organizations and innovation project terminations, while reconciling the research streams on innovation project terminations and resilience is another. It seems adequate and necessary to do so. The termination of an innovation project can be seen as a traumatic trigger event (Kahn, 2003; Välikangas et al., 2009) that represents the core of resilience research (Coutu, 2002). Both research streams therefore entail a gap that the other research area can help close, as resilience research is advanced by analyzing resilience in the context of organizational innovation after an adverse event (e.g. an 
innovation project termination). Furthermore, innovation project terminations are regarded from a human perspective, which may help incorporate 'human costs' in termination decisions.

\section{Managerial implications}

Introducing the concept of IRP can provide managers with guidelines on how to improve employee ability to overcome setbacks such as innovation project termination, or how IRP can be restored after a setback that has negatively affected employee IRP. This is important, as IRP is necessary for the future goal-setting, commitment (Bandura, 1997), and creativity (Amabile et al., 2004; Grzeda and Prince, 1997) of these employees after a termination and, thus, for future innovation project performance. We now deliberately go beyond this study's setting to allude to ways in which organizations and managers may influence project members' IRP components after project termination.

Realistic optimism can be elevated after a failure when the termination reasons are made clear and an outlook for the future is provided (Schneider, 2001). In addition, honest and constructive feedback can enable realistic attributions, which could both take place in an official project debriefing, which seems a very valuable instrument in this context (Von Krogh, 1998).

To reinforce hope among the team members of a terminated project, leaders and other supporters (e.g. colleagues) should help assess the situation and develop future goals (Juntunen and Wettersten, 2006). Furthermore, it is important to ensure that appropriate and not overly difficult goals are set, as these might stimulate employees to embark on actions that are too demanding and difficult. This would increase the likelihood of failure and thus the danger of causing an even greater negative impact on affected individuals (Polivy and Herman, 2000).

The self-esteem of affected individuals can be maintained or restored by executing a termination in a way that appears fair to project team members, as procedural justice has been demonstrated to foster individual self-esteem (Schroth and Shah, 2000). To do so, managers should communicate information about the termination process in a concrete way and should convey accurate future performance expectations (Schroth and Shah, 2000).

Both aspects may also help project members to better evaluate their contributions to the project and to protect their self-efficacy and self-esteem from the consequences of incorrectly attributing project failure to their own shortcomings (McNatt and Judge, 2008). Furthermore, managers should reassure employees that they are capable of success, despite suboptimal circumstances (Pierce et al., 1993), and should avoid managerial actions that may tell employees that they are incompetent and distrusted, such as excessive work rules and oppressive leadership (Pierce et al., 1993). Self-efficacy and outcome expectancy can also be influenced by performance accomplishments (Bandura, 1977). To foster self-efficacy and outcome expectancy, it appears necessary to let project members feel that their capabilities and individual performance did indeed influence project performance and its consequences, for example, through feedback, acknowledgement of good employee performance in terminated projects (Latham, 2001), and/or organizational rewards (Bandura, 1977; Maddux et al., 1986). 
Finally, a sufficiently high risk propensity level may be restored among team members of a terminated innovation project by lessening the fear of future failures and by motivating future achievement by establishing a climate of psychological safety and tolerance for mistakes (Edmondson, 1999). When a failure is experienced as less dramatic, the fear of a future failure is also likely to decrease (Edmondson, 1999).

Our conceptual analysis, complemented by the case study, demonstrates that innovation project terminations may hold very negative consequences for project members as well as companies when it comes to future innovation projects. Yet, management can by various means - effectively support project members and foster their innovative functioning in future innovation projects after a termination. With knowledge of these opportunities, managers can develop initiatives that protect and strengthen IRP after a termination. This benefits employees, as they and their careers will be less impaired by setbacks such as an innovation project termination. This also benefits companies, as employees who maintain their motivation and innovation capabilities after a major setback have the potential to produce more valuable outcomes in terms of future innovation endeavors. Following the research on thriving and post-traumatic growth (Carver, 1998; Westphal and Bonanno, 2007), individuals may even grow or thrive after such a setback. An innovation project termination can become an opportunity when 'project failures' are turned into 'successful failures.' In short, having outlined the IRP construct, we point to aspects managers need to keep in mind when faced with an innovation project termination.

\section{Limitations and outlook}

Reasonable questions often arise concerning the generalization of case study findings beyond the specific context of analysis. Although it is always potentially problematic to argue for generalization from single case studies like this one (Siggelkow, 2007), this study has a number of features that suggest that the mechanisms we found operating in the FI project are likely to apply to innovation project terminations generally. Clearly, the reasons for a termination could influence IRP, but there is nothing unusual in the innovation project context we studied. In fact, the reasons for this specific termination (changes in management and budget problems) are quite common reasons for termination, which lends credence to the proposition that the mechanisms observed in this study might well fit other locales. Moreover, our qualitative analysis builds on seven interviews with representatives from the terminated innovation project. It goes without saying that larger sample sizes might provide additional data. However, the main focus of our qualitative study was to illustrate that innovation project terminations indeed may influence the IRP components, which we are confident that our analyses successfully did. Finally, the qualitative data we analyzed are cross-sectional rather than longitudinal. In the present context, a longitudinal study design, collecting data before and after the termination of an innovation project (and in the perfect case even a subsequent termination) would surely offer substantial benefits.

Directly addressing this aspect, a particularly worthwhile direction for future research is a longitudinal research design that could establish causalities of the identified antecedent variables and their consequences for IRP, and that would demonstrate the 
development and influence of variables over time - i.e. before, during, and after the termination of an innovation project. In this regard, it appears particularly interesting to investigate whether project members who scored higher on the IRP components before the termination are indeed able to cope better and to remain more innovative after a setback. Moreover, identifying and examining possible protective situational and environmental factors would help managers build and sustain IRP in employees. Generally, the development of the IRP construct may be used as a starting point for further empirical investigation of this topic in qualitative and quantitative ways. One next step would be to identify certain characteristics of innovation project terminations that determine what influences such terminations hold for affected individuals' IRP. Aware of such characteristics, managers may plan and coordinate innovation project terminations in a way that minimizes innovation project terminations' negative consequences on IRP and may thus avoid some (if not most) of the human costs of innovation project termination.

\section{Acknowledgements}

The authors would like to thank Associate Editor, Kevin Daniels, and three anonymous reviewers for their valuable comments on prior versions of this article, as well as Julia Backmann and Julia K Fröhlich for their help in this research.

\section{Funding}

This research received no specific grant from any funding agency in the public, commercial, or not-for-profit sectors.

\section{References}

Akgün AE, Lynn GS and Byrne JC (2003) Organizational learning: A socio-cognitive framework. Human Relations 56(7): 839-868.

Amabile TM (1988) A model of creativity and innovation in organizations. Research in Organizational Behavior 10: 123-167.

Amabile TM, Hadley CN and Kramer SJ (2002) Creativity under the gun. Harvard Business Review 80(1): 52-61.

Amabile TM, Schatzl EA, Moneta GB and Kramer SJ (2004) Leader behaviors and the work environment for creativity: Perceived leader support. Leadership Quartlerly 15(1): 5-32.

Avey JB, Luthans F and Jensen SM (2009) Psychological capital: A positive resource for combating employee stress and turnover. Human Resource Management 48(5): 677-693.

Avey JB, Luthans F, Smith RM and Palmer NF (2010a) Impact of positive psychological capital on employee well-being over time. Journal of Occupational Health Psychology 15(1): $17-28$.

Avey JB, Luthans F and Youssef CM (2010b) The additive value of positive psychological capital in predicting work attitudes and behaviors. Journal of Management 36(2): 430-452.

Balachandra R and Brockhoff K (1995) Are R\&D project termination factors universal? Research Technology Management 38(4): 31-34.

Bandura A (1977) Self-efficacy: Toward a unifying theory of behavioral change. Psychological Review 84(2): 191-215.

Bandura A (1982) Self-efficacy mechanism in human agency. Amercian Psychologist 37(2): 122-147.

Bandura A (1986) Social Foundations of Thought and Action: A Social Cognitive Theory. Englewood Cliffs, NJ: Prentice-Hall. 
Bandura A (1988) Organizational applications of social cognitive theory. Australian Journal of Management 13(2): 275-302.

Bandura A (1997) Self-efficacy: The Exercise of Control. New York: Freeman.

Baumeister RF and Exline JJ (2000) Self-control, morality, and human strength. Journal of Social and Clinical Psychology 19(1): 29-42.

Begley TM and Boyd DP (1987) Psychological characteristics associated with performence in entrepreneurial firms and smaller businesses. Journal of Business Venturing 2(1): 79-93.

Bessant J (2008) Dealing with discontinuous innovation: The European experience. International Journal of Technology Management 42(1-2): 36-50.

Bonanno GA, Galea S, Bucciarelli A and Vlahov D (2006) Psychological resilience after disaster - New York City in the aftermath of the September 11th terrorist attack. Psychological Science 17(3): 181-186.

Braden N (1998) Self-esteem at Work. San Francisco, CA: Jossey-Bass.

Buss DM (2000) The evolution of happiness. American Psychologist 55(1): 15-23.

Carver CS (1998) Resilience and thriving: Issues, models, and linkages. Journal of Social Issues 54(2): 245-266.

Clegg SR, Vieira da Cunha J and Pina e Cunha M (2002) Management paradoxes: A relational view. Human Relations 55(5): 483-503.

Cook TD and Campbell DT (1979) Quasi-experimental Design: Design and Analysis Issues for Field Settings. Chicago, IL: Rand McNally.

Corbett AC, Neck HM and DeTienne DR (2007) How corporate entrepreneurs learn from fledgling innovation initiatives: Cognition and the development of a termination script. Entrepreneurship: Theory \& Practice 31(6): 829-852.

Coutu DL (2002) How resilience works. Harvard Business Review 80(5): 46-51.

De Reyck B and Leus R (2008) R\&D project scheduling when activities may fail. IIE Transactions 40(4): 367-384.

Diamond MA (1996) Innovation and diffusion of technology: A human process. Consulting Psychology Journal: Practice and Research 48(4): 221-229.

Dougall AL, Herberman HB, Delahanty DL, Inslicht SS and Baum A (2000) Similarity of prior trauma exposure as a determinant of chronic stress responding to an airline disaster. Journal of Consulting and Clinical Psychology 68(2): 290-295.

Drucker PF (1985) The discipline of innovation. Harvard Business Review 63(3): 67-72.

Edmondson AC (1999) Psychological safety and learning behavior in work teams. Administrative Science Quarterly 44(4): 350-383.

Eisenhardt KM and Graebner ME (2007) Theory building from cases: Opportunities and challenges. Academy of Management Journal 50(1): 25-32.

Eisenhardt KM and Tabrizi BN (1995) Accelerating adaptive processes: Product innovation in the global computer industry. Administrative Science Quarterly 40(1): 84-110.

Erez A and Judge TA (2001) Relationship of core self-evaluations to goal setting motivation, and performance. Journal of Applied Psychology 86(6): 1270-1279.

Flanagan JC (1954) The critical incident technique. Psychological Bulletin 51(4): 327-358.

Freitas AL and Downey G (1998) Resilience: A dynamic perspective. International Journal of Behavioral Development 22(2): 263-285.

Geers AL, Wellman JA and Lassiter GD (2009) Dispositional optimism and engagement: The moderating influence of goal prioritization. Journal of Personality and Social Psychology 96(4): 913-932.

Gibbert M and Ruigrok W (2010) The 'what' and 'how' of case study rigor: Three strategies based on published work. Organizational Research Methods 13(4): 710-737.

Gibbert M, Ruigrok W and Wicki B (2008) What passes as a rigorous case study? Strategic Management Journal 29(13): 1465-1474. 
Glaser BG and Strauss AL (1967) The Discovery of Grounded Theory: Strategies for Qualitative Research. Chicago, IL: Aldine.

Green SG, Welsh MA and Dehler GE (2003) Advocacy, performance, and threshold influences on decisions to terminate new product development. Academy of Management Journal 46(4): 419-434.

Grzeda MM and Prince JB (1997) Career motivation measures: A test of convergent discriminant validity. International Journal of HRM 8(3): 172-196.

Hamel G and Välikangas L (2003) The quest for resilience. Harvard Business Review 81(9): $52-63$.

Hampson SE and Goldberg LR (2006) A first large cohort study of personality trait stability over the 40 years between elementary school and midlife. Journal of Personality and Social Psychology 91(4): 763-779.

Harland L, Harrison W, Jones JR and Reiter-Palmon R (2005) Leadership behaviors and subordinate resilience. Journal of Leadership and Organizational Studies 11(2): 2-14.

Hauschildt J and Kirchmann E (2001) Teamwork for innovation - The 'troika' of promotors. $R \& D$ Management 31(1): 41-49.

Hayward MLA, Forster WR, Sarasvathy SD and Fredrickson BL (2010) Beyond hubris: How highly confident entrepreneurs rebound to venture again. Journal of Business Venturing 25(6): 569-578.

Heatherton TF and Polivy J (1991) Development and validation of scale for measuring state selfesteem. Journal of Personality and Social Psychology 60(6): 895-910.

Hoegl M and Gemuenden HG (2001) Teamwork quality and the success of innovative projects: A theoretical concept and empirical evidence. Organization Science 12(4): 435-449.

Hung SC (2004) Explaining the process of innovation: The dynamic reconciliation of action and structure. Human Relations 57(11): 1479-1497.

Juntunen CL and Wettersten KB (2006) Work hope: Development and initial validation of a measure. Journal of Counseling Psychology 53(1): 94-106.

Kahn WA (2003) The revelation of organizational trauma. Journal of Applied Behavioral Science 39(4): 364-380.

Kester L, Hultink EJ and Lauche K (2009) Portfolio decision-making genres: A case study. Journal of Engineering and Technology Management 26(4): 327-341.

Kumar V, Persaud ANS and Kumar U (1996) To terminate or not an ongoing R\&D project: A managerial dilemma. IEEE Transactions on Engineering Management 43(2): 273-284.

Latham GP (2001) The importance of understanding and changing employee outcome expectancies for gaining commitment to an organizational goal. Personnel Psychology 54(3): 707-716.

Lerner JS and Keltner D (2001) Fear, anger, and risk. Journal of Personality and Social Psychology 81(1): 146-159.

Lombard M, Snyder-Duch J and Campanella Bracken C (2002) Content analysis in mass communication: Assessment and reporting of intercoder reliability. Human Communication Research 28(4): 587-604.

London M (1983) Toward a theory of career motivation. Academy of Management Review 8(4): 620-630.

Luthans F (2002) Positive organizational behavior: Developing and managing psychological strengths. Academy of Management Executive 16(1): 57-72.

Luthans F and Youssef CM (2007) Emerging positive organizational behavior. Journal of Management 33(3): 321-349.

Luthans F, Avey JB, Avolio BJ, Norman SM and Combs GM (2006) Psychological capital development: Toward a micro-intervention. Journal of Organizational Behavior 27(3): 387-393.

Luthans F, Avolio BJ, Avey JB and Norman SM (2007a) Positive psychological capital: Measurement and relationship with performance and satisfaction. Personnel Psychology 60(3): 541-572. 
Luthans F, Norman SM, Avolio BJ and Avey JB (2008) The mediating role of psychological capital in the supportive organizational climate-employee performance relationship. Journal of Organizational Behavior 29(2): 219-238.

Luthans F, Youssef C and Avolio BJ (2007b) Psychological Capital: Developing the Human Competitive Edge. New York and Oxford: Oxford University Press.

Luthar SS, Cicchetti D and Becker B (2000) The construct of resilience: A critical evaluation and guidelines for future work. Child Development 71(3): 543-562.

McCrae RR and Costa PT Jr (1982) Self-concept and the stability of personality: Cross-sectional comparisons of self-reports and ratings. Journal of Personality \& Social Psychology 43(6): $1282-1292$.

McCrae RR and John OP (1992) An introduction to the five-factor model and its applications. Journal of Personality 60(2): 175-215.

McFarland C and Ross M (1982) Impact of causal attributions on affective reactions to success and failure. Journal of Personality and Social Psychology 43(5): 937-946.

McNatt DB and Judge TA (2008) Self-efficacy intervention, job attitudes, and turnover: A field experiment with employees in role transition. Human Relations 61(6): 783-810.

Maddux JE, Norton LW and Stoltenberg CD (1986) Self-efficacy expectancy, outcome expectancy, and outcome value: Relative effects on behavioral intentions. Journal of Personality and Social Psychology 51(4): 783-789.

Mannheim B, Baruch Y and Tal J (1997) Alternative models for antecedents and outcomes of work centrality and job satisfaction of high-tech personnel. Human Relations 50(12): 1537-1562.

Masten AS (2001) Ordinary magic - resilience processes in development. Amercian Psychologist 56(3): 227-238.

Masten AS and Reed MJ (2002) Resilience in development. In: Snyder CR and Lopez SJ (eds) Handbook of Positive Psychology. New York: Oxford University Press, 74-88.

Miron E, Erez M and Naveh E (2004) Do personal characteristics and cultural values that promote innovation, quality, and efficiency compete or complement each other? Journal of Organizational Behavior 25(2): 175-199.

Moore S, Grunberg L and Greenberg E (2004) Repeated downsizing contact: The effects of similar and dissimilar layoff experiences on work and well-being outcomes. Journal of Occupational Health Psychology 9(3): 247-257.

Mumford MD and Gustafson SB (1988) Creativity syndrome: Integration, application, and innovation. Psychological Bulletin 103(1): 27-43.

Neundorf KA (2002) The Content Analysis Guidebook. London: SAGE.

Noe RA, Noe AW and Bachhuber JA (1990) An investigation of the correlates of career motivation. Journal of Vocational Behavior 37(3): 340-356.

O'Connor GC and McDermott CM (2004) The human side of radical innovation. Journal of Engineering and Technology Management 21(1-2): 11-30.

Ollier-Malaterre A (2010) Contributions of work-life and resilience initiatives to the individual/ organization relationship. Human Relations 63(1): 41-62.

Ong AD, Bergeman CS, Bisconti TL and Wallace KA (2006) Psychological resilience, positive emotions, and successful adaptation to stress in later life. Journal of Personality and Social Psychology 91(4): 730-749.

Peterson C (2000) The future of optimism. Amercian Psychologist 55(1): 44-55.

Phillips JM and Gully SM (1997) Role of goal orientation, ability, need for achievement, and locus of control in the self-efficacy and goal-setting process. Journal of Applied Psychology 82(5): 792-802.

Pierce JL, Gardner DG, Dunham RB and Cummings LL (1993) Moderation by organization-based self-esteem of role condition-employee response relationships. Academy of Management Journal 36(2): 271-288. 
Polivy J and Herman CP (2000) The false-hope syndrome: Unfulfilled expectations of self-change. Current Directions in Psychological Science 9(4): 128-131.

Powley EH (2009) Reclaiming resilience and safety: Resilience activation in the critical period of crisis. Human Relations 62(9): 1289-1326.

Range LM and Penton SR (1994) Hope, hopelessness, and suicidality in college students. Psychological Reports 75(1): 456-458.

Richardson GE (2002) The metatheory of resilience and resiliency. Journal of Clinical Psychology 58(3): 307-321.

Riggs ML and Knight PA (1994) The impact of perceived group success-failure on motivational beliefs and attitudes: A causal model. Journal of Applied Psychology 79(5): 755-766.

Rotter J (1966) Generalized expectancies for internal versus external control of reinforcement. Psychological Monographs 80: 1-28.

Rush MC, Schoel WA and Barnard SM (1995) Psychological resiliency in the public sector: 'Hardiness' and pressure for change. Journal of Vocational Behavior 46(1): 17-39.

Rybowiak V, Gerst H, Frese M and Batinic B (1999) Error Orientation Questionnaire (EOQ): Reliability, validity, and different language equivalence. Journal of Organizational Behavior 20(4): 527-547.

Schmidt JB and Calantone RJ (1998) Are really new product development projects harder to shut down? Journal of Product Innovation Management 15(2): 111-123.

Schneider B (1983) Interactional psychology and organizational behavior. Research in Organizational Behavior 5: 1-31.

Schneider SL (2001) In search of realistic optimism. meaning, knowledge, and warm fuzziness. Amercian Psychologist 56(3): 250-263.

Schroth HA and Shah PP (2000) Procedures: Do we really want to know them? An examination of the effects of procedural justice on self-esteem. Journal of Applied Psychology 85(3): 462-471.

Seligman MEP (1998) Learned Optimism. New York: Pocket Books.

Seligman MEP and Csikszentmihalyi M (2000) Positive psychology: An introduction. American Psychologist 55(1): 5-14.

Seligman MEP, Castellon C, Cacciola J, Schulman P, Luborsky L, Ollove M and Downing R (1988) Explanatory style change during cognitive therapy for unipolar depression. Journal of Abnormal Psychology 97(1): 13-18.

Sethi R and Sethi A (2009) Can quality-oriented firms develop innovative new products? Journal of Product Innovation Management 26(2): 206-221.

Shenkar O and Yan A (2002) Failure as a consequence of partner politics: Learning from the life and death of an international cooperative venture. Human Relations 55(5): 565-601.

Shepherd DA (2009) Grief recovery from the loss of a family business: A multi- and meso-level theory. Journal of Business Venturing 24(1): 81-97.

Shepherd DA and Cardon M (2009) Negative emotional reactions to project failure and the selfcompassion to learn from experience. Journal of Management Studies 46(8): 923-949.

Shepherd DA and Kuratko DF (2009) The death of an innovative project: How grief recovery enhances learning. Business Horizons 52(5): 451-458.

Shepherd DA, Covin JG and Kuratko DF (2009a) Project failure from corporate entrepreneurship: Managing the grief process. Journal of Business Venturing 24(6): 588-600.

Shepherd DA, Wiklund J and Haynie JM (2009b) Moving forward: Balancing the financial and emotional costs of business failure. Journal of Business Venturing 24(3): 134-148.

Siggelkow N (2007) Persuasion with case studies. Academy of Management Journal 50(1): 20-24.

Silverman D (2000) Doing Qualitative Research: A Practical Handbook. Thousand Oaks, CA: SAGE.

Simon M, Houghton SM and Aquino K (2000) Cognitive biases, risk perception, and venture formation: How individuals decide to start companies. Journal of Business Venturing 15(2): 113-134. 
Sivanathan N, Molden DC, Galinsky AD and Ku G (2008) The promise and peril of selfaffirmation in de-escalation of commitment. Organizational Behavior and Human Decision Processes 107(1): 1-14.

Snyder CR, Harris C, Anderson JR, Holleran SA, Irving IM., Sigmon ST, Yoshinobu L, Gibb J, Langelle C and Harney P (1991) The will and the ways: Development and validation of an individual-difference measure of hope. Journal of Personality and Social Psychology 60(4): $570-585$.

Snyder CR, Sympson SC, Ybasco FC, Borders TF, Babyak MA and Higgins RL (1996) Development and validation of the State Hope Scale. Journal of Personality and Social Psychology 70(2): 321-335.

Stajkovic AD (2006) Development of a core confidence-higher order construct. Journal of Applied Psychology 91(6): 1208-1224.

Stajkovic AD and Luthans F (1998) Social cognitive theory and self-efficacy: Going beyond traditional motivational and behavioral approaches. Organizational Dynamics 26(5): 62-74.

Sutcliffe K and Vogus T (2003) Organizing for resilience. In: Cameron KS, Dutton JE and Quinn REQ (eds) Positive Organizational Scholarship: Foundations of a New Discipline. San Francisco, CA: Berrett-Koehler, 94-110.

Taylor SE (1983) Adjustment to threatening events: A theory of cognitive adaptation. American Psychologist 38(11): 1161-1173.

Tierney P and Farmer SM (2002) Creative self-efficacy: Its potential antecedents and relationship to creative performance. Academy of Management Journal 45(6): 1137-1148.

Tiger L (1979) Optimism: The Biology of Hope. New York: Simon \& Schuster.

Tjosvold D and Ziyou Y (2007) Group risk taking: The constructive role of controversy in China. Group \& Organization Management 32(6): 653-674.

Tugade MM and Fredrickson BL (2004) Resilient individuals use positive emotions to bounce back from negative emotional experiences. Journal of Personality and Social Psychology 86(2): 320-333.

Välikangas L, Hoegl M and Gibbert M (2009) Why learning from failure isn't easy (and what to do about it): Innovation trauma at Sun Microsystems. European Management Journal 27(4): $225-233$.

Van de Ven AH (1986) Central problems in the management of innovation. Management Science 32(5): 590-607.

Van de Ven AH and Polley D (1992) Learning while innovating. Organization Science 3(1): 92-116.

Verona G (1999) A resource-based view of product development. Academy of Management Review 24(1): 132-142.

Von Krogh G (1998) Care in knowledge creation. California Management Review 40(3): 133-153.

Wanberg CR and Banas JT (2000) Predictors and outcomes of openness to changes in a reorganizing workplace. Journal of Applied Psychology 85(1): 132-142.

Weick KE (1993) The collapse of sensemaking in organizations: The Mann Gulch disaster. Administrative Science Quarterly 38(4): 628-652.

Weiner B (1985) An attributional theory of achievement motivation and emotion. Psychological Review 92(4): 548-573.

Wengraf T (2001) Qualitative Research Interviewing: Biographic Narrative and Semi-structured Methods. London: SAGE.

Westphal M and Bonanno GA (2007) Posttraumatic growth and resilience to trauma: Different sides of the same coin or different coins? Applied Psychology: An International Review 56(3): 417-427.

Witkin HA and Goodenough DR (1981) Cognitive Styles - Essence and Origins: Field Dependence and Field Independence. New York: International University Press. 
Woodman RW, Sawyer JE and Griffin RW (1993) Toward a theory of organizational creativity. Academy of Management Review 18(2): 293-321.

Yin RK (2003) Case Study Research: Design and Methods, Thousand Oaks, CA: SAGE.

Youssef CM and Luthans F (2007) Positive organizational behavior in the workplace: The impact of hope, optimism, and resilience. Journal of Management 33(5): 774-800.

Gisa Moenkemeyer is a PhD candidate at WHU - Otto Beisheim School of Management, Vallendar, Germany. Her doctoral dissertation focuses on project terminations and resilience in the innovation context. She regularly conducts seminars and workshops for multi-national companies in the area of human factors training and strategy. [Email: gisa.moenkemeyer@whu.edu]

Martin Hoegl is Professor at the Ludwig-Maximilians-Universität München, Germany, where he heads the Institute of Leadership and Organization. His main research interests include leadership, collaboration, and innovation in organizations. He has published in Academy of Management Journal, Decision Sciences, Human Relations, Human Resource Management, Journal of Business Ethics, Journal of International Business Studies, Journal of Management, Journal of Management Studies, Journal of Product Innovation Management, MIT Sloan Management Review, Organization Science, Research Policy, and other journals. [Email: hoegl@1mu.de]

Matthias Weiss is Assistant Professor at the Institute of Leadership and Organization at LudwigMaximilians-Universität München, Germany. His research interests are in the area of creativity and innovation. In particular, he focuses on the role of resources, teamwork, and perception in the innovation process. He has published his research in international journals such as The Journal of Product Innovation Management. [Email: weiss@bwl.lmu.de] 